\title{
Erratum to: Semisynthesis and biological evaluation of prenylated resveratrol derivatives as multi-targeted agents for Alzheimer's disease
}

\author{
Thanchanok Puksasook $^{1} \cdot$ Shinya Kimura ${ }^{2} \cdot$ Sarin Tadtong $^{3} \cdot$ Jutamas Jiaranaikulwanitch $^{4}$. \\ Jaturong Pratuangdejkul ${ }^{5} \cdot$ Worawan Kitphati $^{6} \cdot$ Khanit Suwanborirux $^{7} \cdot$ Naoki Saito $^{2}$. \\ Veena Nukoolkarn ${ }^{1}$
}

Published online: 11 July 2017

(C) The Japanese Society of Pharmacognosy and Springer Japan KK 2017

\section{Erratum to: J Nat Med \\ DOI 10.1007/s11418-017-1097-2}

In the original publication of the article, the chemical structures of compounds $3 \mathrm{a}-\mathrm{d}, 4 \mathrm{a}-\mathrm{c}$, and $5 \mathrm{a}-\mathrm{c}$ were incorrect. The correct chemical structures are given below.

The original article has also been updated.

The online version of the original article can be found under doi:10.1007/s11418-017-1097-2.

Veena Nukoolkarn

veena.nuk@mahidol.ac.th;

Thanchanok.puk@student.mahidol.ac.th

1 Department of Pharmacognosy, Faculty of Pharmacy, Mahidol University, Bangkok 10400, Thailand

2 Graduate School of Pharmaceutical Sciences, Meiji Pharmaceutical University, Tokyo 204-8588, Japan

3 Department of Pharmacognosy, Faculty of Pharmacy, Srinakharinwirot University, Nakhon Nayok 26120, Thailand

4 Department of Pharmaceutical Sciences, Faculty of Pharmacy, Chiang Mai University, Chiang Mai 50200, Thailand

5 Department of Microbiology, Faculty of Pharmacy, Mahidol University, Bangkok 10400, Thailand

6 Department of Physiology, Faculty of Pharmacy, Mahidol University, Bangkok 10400, Thailand

7 Department of Pharmacognosy and Pharmaceutical Botany, Faculty of Pharmaceutical Sciences, Center for Bioactive Natural Products from Marine Organisms and Endophytic Fungi (BNPME), Chulalongkorn University, Bangkok 10330, Thailand 
Preparation of compounds 3a-d<smiles>CCOc1ccc(C=Cc2cc(OCC)cc(OCC)c2)cc1</smiles>

3a

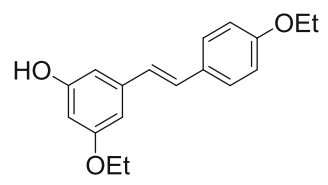

3b<smiles>CCOc1cc(O)cc(/C=C/c2ccc(O)cc2)c1</smiles>

$3 c$

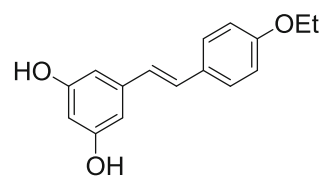

3d

\section{Preparation of compounds 4a-c}

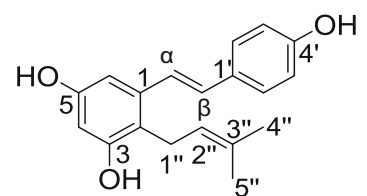

$4 a$

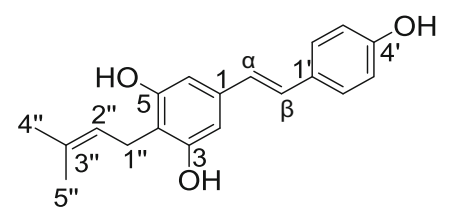

4b

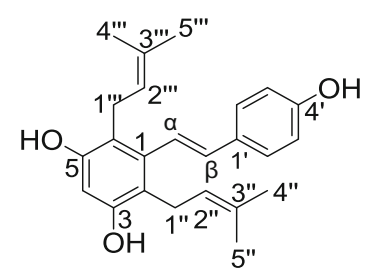

4c

Preparation of compounds 5a-c

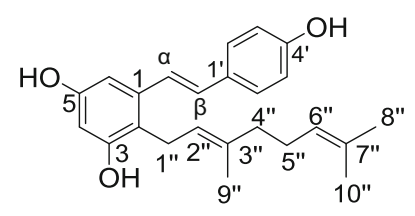

$5 a$

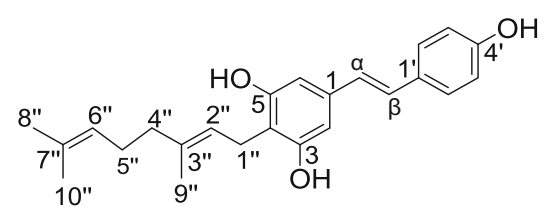

$5 b$

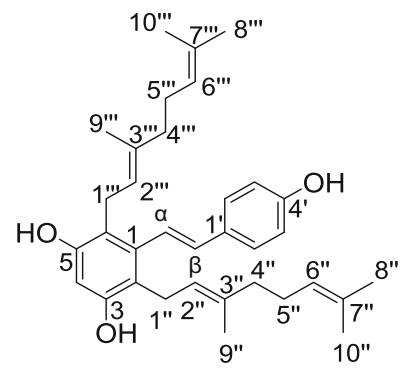

$5 c$ 